REVISTA

\title{
LODO DE CURTUME ADICIONADO EM SUBSTRATO COMERCIAL PARA PRODUÇÃO DE MUDAS DE PIMENTA MALAGUETA
}

\author{
TANNERY SLUDGE ADDED IN COMMERCIAL SUBSTRATE FOR \\ PRODUCTION OF CHICKEN PEPPER SEEDLINGS
}

Sávio da Silva Berilli ${ }^{1}$

Carla Basílio Monteiro ${ }^{2}$

Ana Terra Bravim dos Santos ${ }^{3}$

Fernanda Emanuele Silva Costa ${ }^{4}$

Ringo Souza Batista ${ }^{5}$

Hélio Orlando Menegueli ${ }^{6}$

Francisco José Valim Olmo ${ }^{7}$

Vinicius Rodrigues Ferreira ${ }^{8 *}$

\begin{abstract}
${ }^{1}$ Instituto Federal de Educação, Ciência e Tecnologia do Espirito Santo - IFES, Campus de Alegre- ES. E-mail: berilli@gmail.com

${ }^{2}$ Instituto Federal de Educação, Ciência e Tecnologia do Espirito Santo - IFES, Campus de Alegre- ES. E-mail: carla.ccaufes@gmail.com

${ }^{3}$ Instituto Federal de Educação, Ciência e Tecnologia do Espirito Santo - IFES, Campus de Alegre- ES. E-mail: anaterrabravim@hotmail.com

${ }^{4}$ Instituto Federal de Educação, Ciência e Tecnologia do Espirito Santo - IFES, Campus de Alegre- ES. E-mail: fernandatuim@yahoo.com.br

${ }^{5}$ Instituto Federal de Educação, Ciência e Tecnologia do Espirito Santo - IFES, Campus de Alegre- ES. E-mail: ringo.batista68@gmail.com

${ }^{6}$ Instituto Federal de Educação, Ciência e Tecnologia do Espirito Santo - IFES, Campus de Alegre- ES. E-mail: helio@ organicaconsultoria.com.br

${ }^{7}$ Instituto Federal de Educação, Ciência e Tecnologia do Espirito Santo - IFES, Campus de Alegre- ES. E-mail: fjvolmo@hotmail.com

${ }^{8}$ Instituto Federal de Educação, Ciência e Tecnologia do Espirito Santo - IFES, Campus de Alegre- ES. E-mail: rodrigues.ufes@gmail.com

*Autor de correspondência
\end{abstract}

Artigo submetido em 28/03/2020, aceito em 05/05/2020 e publicado em 28/08/2020.

Resumo: O aproveitamento de resíduos agroindustriais, embora pouco recorrente, seria uma significativa estratégia econômica e benéfica ao meio ambiente. Tais materiais apresentam elevadas porções de matéria orgânica e nutrientes, indicando alto potencial em utilização agrícola. A respeito desse assunto, o objetivo deste trabalho é avaliar o desenvolvimento e a qualidade de mudas de pimenta malagueta, cultivadas em seis diferentes substratos, contendo proporções de 0 a $90 \%$ de lodo de curtume em substrato comercial Bioplant ${ }^{\circledR}$, além do substrato testemunha, o Provaso ${ }^{\circledR}$. Aos 21 dias após a semeadura, foi contabilizado o número de plântulas emergidas e, aos 42 dias, as características de desenvolvimento e qualidade de mudas. Para a maioria das variáveis analisadas, o lodo de curtume nos substratos promoveu um bom desenvolvimento das plântulas de pimenteira, apresentando desempenho semelhante ao Provaso ${ }^{\circledR}$. Todavia, o aumento das porções de lodo, aplicadas acima de um nível ótimo, tem efeito negativo, sendo observado declínio nos parâmetros de crescimento e qualidade das plântulas. Além disso, observou-se que o Bioplant ${ }^{\circledR}$ necessita de 
suplementação mineral para atender as necessidades iniciais das plântulas, sendo essa basicamente sustentada pelo lodo de curtume adicionado a mistura do substrato. Por fim, a adição entre 53 e $65 \%$ de lodo de curtume ao substrato comercial Bioplant ${ }^{\circledR}$, para produção de mudas de pimenta malagueta, mostrou-se viável agronomicamente, promovendo uma boa qualidade e satisfatório desenvolvimento das mudas.

Palavras-chave: propagação; matéria orgânica; resíduo alternativo; sustentabilidade; Capsicum frutescens $\mathrm{L}$.

\begin{abstract}
The use of agro-industrial waste is not very recurrent, although it is economically viable and beneficial to the environment. Such materials have high portions of organic matter and nutrients, indicating high potential for agricultural use. Therefore, the objective of this research was to evaluate the development and quality of chili pepper seedlings, grown on six different substrates, containing proportions from 0 to $90 \%$ of tannery sludge in a commercial Bioplant ${ }^{\circledR}$ substrate, in addition to the control substrate, Provaso®. Twenty-one days after sowing, the number of emerged seedlings was counted, and in 42 days we counted the characteristics of seedling development and quality. For most of the analyzed variables, the tannery sludge in the substrates promoted a good development of pepper seedlings, presenting a similar performance to Provaso®. However, the increase in sludge portions, applied above an optimum level, has a negative effect, with a decline in growth parameters and seedling quality. In addition, it was observed that Bioplant ${ }^{\circledR}$ needs mineral supplementation to meet the initial needs of the seedlings, which is basically supported by the tannery sludge added to the substrate mixture. Finally, the addition of 53 to $65 \%$ of tannery sludge to the commercial substrate Bioplant ${ }^{\circledR}$, for the production of chili pepper seedlings, proved to be viable agronomically, promoting good quality and satisfactory seedling development.
\end{abstract}

Keywords: propagation; organic matter; alternative residue; sustainability; Capsicum frutescens L.

\section{INTRODUÇÃO}

Em função dos sistemas de produção agrícolas e industriais, somados à urbanização, são gerados em escala crescente, diversos resíduos, os quais quando descartados inadequadamente, possuem a capacidade de causar problemas ambientais (ZANELLO; CARDOSO, 2016). Por outro lado, o aproveitamento de resíduos agroindustriais é pouco recorrente, embora seja viável economicamente e benéfico ao meio ambiente (COMÉRIO et al., 2019).

Por esse motivo, a aplicação de resíduos na composição de substratos tem sido constantemente objeto de pesquisas que buscam a reutilização dos nutrientes presentes nesses materiais. Tal prática promove a redução de custo de produção e, ao mesmo tempo, minimizam os impactos ambientais negativos da geração de rejeitos (ARAÚJO et al., 2017).
Neste contexto, o lodo de curtume apresenta-se como uma solução tecnicamente viável à agricultura (BERILLI et al., 2018a; 2019), uma vez que é um resíduo composto por matéria orgânica e elementos químicos que servem de condicionadores do solo (SHARMA et al., 2017). Contudo, o lodo de curtume pode conter elevada concentração de cromo, sulfeto e sódio, devendo ter cuidado com sua utilização (QUADRO et al., 2018; COMÉRIO et al., 2019).

Por isso, a aplicação desse resíduo tem sido estudada na composição de substrato de mudas e adubação (ALMEIDA et al., 2017; BERILLI et al., 2018b; 2019; ROCHA et al., 2019; SILVA et al., 2019), além do reflorestamento e na recuperação de áreas degradadas (SALES et al., 2017; 2018a). Um desses estudos identificou que o lodo de curtume, em combinação com substrato comercial para produção de mudas de pimenta biquinho, garantiu um bom 
desenvolvimento e qualidade das plântulas (ALMEIDA et al., 2017).

Experimentos de Berilli et al. (2019) também verificaram que o lodo de curtume e composto de lixo urbano promoveram o desenvolvimento fisiológico e qualidade de mudas de pimenta doce com resultados superiores ao uso do substrato comercial, indicando que lodo de curtume é um potencial complemento de substratos.

Além disso, o lodo de curtume associado à sua matéria orgânica, tanto compostada, quanto em mistura com substratos comerciais, influenciaram na emergência e crescimento de plântulas de pimenta (SILVA et al., 2011). Demais estudos também confirmam a importância desse resíduo, para produção de mudas em diferentes culturas como abacaxi (COMÉRIO et al., 2019), café conilon (SALES et al., 2018a), maracujá-amarelo (SILVA et al., 2019) e, pimenteira ornamental (BERILLI et al., 2014; 2015).

Dentre as hortaliças, as pimentas do gênero Capsicum são amplamente cultivadas no Brasil e vistas com grande importância, em virtude de suas características de rentabilidade. Elas são produzidas por pequenos agricultores familiares, gerando emprego e renda à população do campo (OZA et al., 2018). Cabe ressaltar que esse gênero possui ampla diversidade genética, com diversos usos, além da alimentícia, servindo de matéria prima para as indústrias farmacêuticas e de cosméticos. Além do mais, podem ser aproveitadas como plantas ornamentais (NEITZKE et al., 2016).

Para tanto, na cadeia produtiva de hortaliças, a formação de mudas é uma das fases mais importantes para o ciclo da cultura. Essa etapa inicial influencia diretamente no desenvolvimento final da planta, tanto do ponto de vista nutricional como produtivo, existindo uma relação direta entre mudas sadias e produção a campo (OLIVEIRA et al., 2018). Neste sentido, em função das propriedade nutricionais, o lodo de curtume possui potencial de utilização em viveiros, já que pode acelerar o crescimento das mudas, reduzindo custos com aquisição de adubos convencionais.

Por sua vez, o uso do lodo de curtume na atividade agrícola promove benefícios que vão além dos aspectos econômicos, devido ao aproveitamento de um resíduo potencialmente nocivo ao meio ambiente e de difícil descarte, devendo sua aplicação ser aparada pela pesquisa. Portanto, com o presente trabalho, objetivou-se avaliar o desenvolvimento e qualidade de mudas de pimenta malagueta (Capsicum frutescens L.), cultivadas em substratos com diferentes proporções de lodo de curtume e substrato comercial.

\section{MATERIAIS E MÉTODOS}

O experimento foi conduzido no Instituto Federal de Educação, Ciência e Tecnologia do Espírito Santo - Campus de Alegre, localizado na região do Caparaó, município de Alegre, estado do Espírito Santo, com coordenadas geográficas de $20^{\circ} 45^{\prime} 44^{\prime \prime}$ ' de latitude Sul, $41^{\circ} 27^{\prime} 42,83^{\prime}$ ' de longitude Oeste e altitude média de $134 \mathrm{~m}$. Utilizou-se de casa de vegetação coberta com tela tipo sombrite com 50\% de sombreamento, dotada de sistema de irrigação por microaspersão automatizado, programado para irrigar 2 vezes ao dia.

Foi utilizado o delineamento em blocos casualizados, em 6 níveis de diferentes proporções de lodo de curtume e/ou substrato comercial Bioplant ${ }^{\circledR}$, além de um segundo substrato comercial, o Provaso $^{\circledR}$ (Tabela 1).

O lodo de curtume foi cedido pela empresa Capixaba Couros LTDA, localizada no município de Baixo Guandu/ES. Esse é um resíduo do efluente do curtimento do couro bovino, proveniente dos tanques de decantação do processo de tratamento de água residuária dos curtumes. O material orgânico presente foi prédecomposto por processo anaeróbico e após retirada do lodo (material decantado) passou 
por desidratação ao ar livre (exposição ao sol).

Tabela 1: Descrição dos tratamentos contendo lodo de curtume e/ou Bioplant ${ }^{\circledR}$ e suas diferentes proporções, tendo como testemunha o Provaso ${ }^{\circledR}$.

\begin{tabular}{cc}
\hline Tratamentos & $\begin{array}{c}\text { Componente do } \\
\text { Substrato }\end{array}$ \\
\hline TB & $100 \%$ de Bioplant ${ }^{\circledR}$ \\
TL10 & $10 \%$ de lodo de curtume \\
& $+90 \%$ de Bioplant ${ }^{\circledR}$ \\
TL30 & $30 \%$ de lodo de curtume \\
& $+75 \%$ de Bioplant ${ }^{\circledR}$ \\
TL50 & $50 \%$ de lodo de curtume \\
& $+50 \%$ de Bioplant ${ }^{\circledR}$ \\
TL70 & $70 \%$ de lodo de curtume \\
& $+25 \%$ de Bioplant ${ }^{\circledR}$ \\
TL90 & $90 \%$ de lodo de curtume \\
TP & $+10 \%$ de Bioplant ${ }^{\circledR}$ \\
\end{tabular}

Nas tabelas 2, 3 e 4 são apresentadas as composições dos substratos comerciais e do resíduo industrial em estudo.

Tabela 2: Características físicas e químicas do lodo de curtume

\begin{tabular}{ccc}
\hline Parâmetro & Unidade & Resultado \\
$\mathrm{MO}^{1}$ & $\mathrm{~g} \mathrm{dm}^{-3}$ & 293,1 \\
$\mathrm{MO}^{2}$ & $\mathrm{~g} \mathrm{dm}^{-3}$ & 110,2 \\
$\mathrm{C}^{3}$ & $\mathrm{~g} \mathrm{dm}^{-3}$ & 61,2 \\
$\mathrm{C} / \mathrm{N}$ & - & $4 / 1$ \\
$\mathrm{C}$ & $\mathrm{g} \mathrm{dm}^{-3}$ & 61,2 \\
$\mathrm{~N}$ & $\mathrm{~g} \mathrm{dm}^{-3}$ & 17,3 \\
$\mathrm{P}$ & $\mathrm{g} \mathrm{dm}^{-3}$ & 7,6 \\
$\mathrm{~K}$ & $\mathrm{~g} \mathrm{dm}^{-3}$ & 0,6 \\
$\mathrm{Ca}$ & $\mathrm{g} \mathrm{dm}^{-3}$ & 230,2 \\
$\mathrm{Mg}$ & $\mathrm{g} \mathrm{dm}^{-3}$ & 21,3 \\
$\mathrm{~S}$ & $\mathrm{~g} \mathrm{dm}^{-3}$ & 13,2 \\
$\mathrm{Na}$ & $\mathrm{g} \mathrm{dm}^{-3}$ & 8,0 \\
$\mathrm{Cr}$ & $\mathrm{g} \mathrm{dm}^{-3}$ & 40,0 \\
$\mathrm{~B}$ & $\mathrm{~g} \mathrm{dm}^{-3}$ & 0,281 \\
\hline${ }^{1}$ Matéria orgânica & total; $^{2}$ Matéria & orgânica \\
compostável; ${ }^{3}$ Carbono orgânico. Fonte: o autor
\end{tabular}

Tabela 3: Características físicas e químicas do substrato comercial Bioplant ${ }^{\circledR}$

\begin{tabular}{ccc}
\hline Parâmetro & Unidade & Resultado \\
$\mathrm{pH}^{1}$ & - & 5,62 \\
$\mathrm{~N}_{\mathrm{T}}$ & $\mathrm{g} \mathrm{dm}^{-3}$ & 6,2 \\
$\mathrm{P}$ & $\mathrm{g} \mathrm{dm}^{-3}$ & 15,5 \\
$\mathrm{~K}$ & $\mathrm{~g} \mathrm{dm}^{-3}$ & 4,4 \\
$\mathrm{Ca}$ & $\mathrm{g} \mathrm{dm}^{-3}$ & 18,4 \\
$\mathrm{CO}$ & $\mathrm{g} \mathrm{dm}^{-3}$ & 210 \\
$\mathrm{MO}$ & $\mathrm{g} \mathrm{dm}^{-3}$ & 522,1 \\
$\mathrm{C} / \mathrm{N}$ & - & 33,9 \\
\hline
\end{tabular}

${ }^{1} \mathrm{pH}$ em CaCl $2 ; \mathrm{N}_{\mathrm{T}}=$ nitrogênio total; $\mathrm{CO}_{\mathrm{T}}=$ carbono orgânico total; $\mathrm{MO}=$ matéria orgânica. Fonte: o fabricante

Tabela 4: Características químicas do composto comercial Provaso ${ }^{\circledR}$

\begin{tabular}{ccc} 
Parâmetro & Unidade & Resultado \\
$\mathrm{pH}$ & - & 6,5 \\
$\mathrm{C} / \mathrm{N}$ & - & 15 \\
$\mathrm{CTC} / \mathrm{C}$ & - & 13 \\
$\mathrm{U}^{1}$ & $\%$ & 50 \\
$\mathrm{~N}_{\mathrm{T}}$ & $\mathrm{g} \mathrm{dm}^{-3}$ & 10 \\
$\mathrm{CO}_{\mathrm{T}}$ & $\mathrm{g} \mathrm{dm}^{-3}$ & 150 \\
$\mathrm{CTC}$ & $\mathrm{cmol}_{\mathrm{c} \mathrm{dm}} \mathrm{dm}^{-3}$ & 19,5 \\
\hline
\end{tabular}

${ }^{1}$ Umidade; $\mathrm{N}_{\mathrm{T}}=$ nitrogênio total; $\mathrm{CO}_{\mathrm{T}}=$ carbono orgânico total. Fonte: o fabricante

Cada parcela experimental foi composta por quatro repetições de dezesseis plântulas, totalizando 448 mudas. A semeadura foi realizada em bandejas de 128 células previamente preenchidas com os substratos, adicionando-se 3 sementes de pimenta malagueta (Capsicum frutescens L.) por célula, da marca Feltrin ${ }^{\circledR}$, com taxa de germinação entre $82 \%$, possuindo 99,2 de pureza. A contagem do número de plântulas emergidas ocorreu aos 21 dias após a semeadura, sendo consideradas aquelas que apresentavam os cotilédones totalmente livres e normais (LABOURIAU, 1983), seguida de desbaste, deixando-se uma plântula por célula, a mais vigorosa. Aos 42 dias as mudas atingiram o ponto de transplantio, sendo coletadas dez 
plântulas de cada repetição, realizando-se as seguintes avaliações: número de folhas (NF); diâmetro do caule (DC); altura da plântula (AP); comprimento da raiz e; diâmetro da copa (DCOP). Também foram feitas avaliações gravimétricas em balança analítica $(0,001 \mathrm{~g})$ da matéria fresca da parte aérea (MFPA) (mg plântula ${ }^{-1}$ ) e matéria fresca das raízes (MFR) (mg plântula ${ }^{-1}$ ), que foram levadas para secagem em estufa a 65 ${ }^{\circ} \mathrm{C}$ por $72 \mathrm{~h}$ para posterior aferição dos valores de matéria seca de parte aérea (MSPA) (mg plântula ${ }^{-1}$ ) e matéria seca de raiz (MSR) (mg plântula ${ }^{-1}$ ), totalizando a matéria seca total da plântula (MST) (mg plântula $^{-1}$ ). O Índice de Qualidade de Dickson (IQD) (Dickson et al., 1960), foi calculado por meio da fórmula: IQD = MST / [(AP / DC) + (MSPA/MSR $)]$.

Os dados foram submetidos à análise de variância pelo teste $\mathrm{F}$ e, havendo significância, as médias foram comparadas pelo teste de Dunnett a $5 \%$ de probabilidade. Também foram realizadas regressões, quando significativas, para as concentrações de lodo de curtume. Todo o procedimento estatístico foi realizado pelo programa estatístico $\mathrm{R}$ ( $R$ core team, 2016).

\section{RESULTADOS E DISCUSSÃO}

De modo geral, o uso do lodo de curtume desidratado na composição dos substratos promoveu um bom desenvolvimento das plântulas de pimenta malagueta, apresentando resultado semelhante ao tratamento com Provaso ${ }^{\circledR}$ (Tabelas 5 e 6). O substrato comercial Provaso ${ }^{\circledR}$ foi o que resultou no menor índice de emergência $(28,1 \%)$, portanto muito aquém daquele informado pelo fabricante, que é entre 82 e 99,2\%.

$\mathrm{O}$ baixo valor de emergência compromete qualquer sistema de produção de mudas, como observado por Almeida et al. (2017) em mudas de pimenta biquinho, que relatam que o interessante é conseguir maiores índices de emergência, até mesmo com substratos alternativos, uma vez que resultam em menores gastos com insumos. Mais do que isso, a composição química e orgânica do substrato influencia o estado nutricional e o desenvolvimento das mudas, após a germinação (DIAS et al., 2008).

Todavia, um bom substrato não deve ser considerado somente quanto ao desenvolvimento das mudas, pois depende de fatores relacionados às condições ótimas para o processo germinativo (DIAS et al., 2008). A princípio isso indica o potencial do lodo de curtume compostado ou associado a substratos comerciais, uma vez que percentagem de emergência das plântulas foi superior em todos os tratamentos quando comparados ao Provaso®.

O número de folhas nos tratamentos com 30, 50 e $70 \%$ de lodo de curtume, além do substrato Provaso $\AA$, expressaram o momento ideal de transplantio que é quando as mudas de pimenta possuem de 4 a 6 folhas (ROCHA NETO et al., 2005). O baixo valor de altura de plântula do tratamento TB em relação ao Provaso $®$, pode significar prejuízos no dossel final e na produção dessa hortaliça, pois serão as plântulas mais afetadas no processo de transplantio (DASSIE et al., 2017).

Por outro lado, a adição de lodo de curtume ao Bioplant ${ }^{\circledR}$ promoveu efeitos positivos na altura da plântula, tanto quanto os apresentados pelo Provaso ${ }^{\circledR}$, possivelmente em virtude das propriedade químicas desse resíduo que apresenta teores nutricionais consideráveis, principalmente de $\mathrm{Ca}, \mathrm{Mg}, \mathrm{N}$ e $\mathrm{P}$ (Tabela 2), que proporcionam melhores condições ao desenvolvimento das mudas de pimenta.

Esse mesmo resultado foi observado para diâmetro do caule, o qual o tratamento com apenas Bioplant ${ }^{\circledR}$ proporcionou a menor média desse parâmetro em relação ao Provaso®. Os demais tratamentos apresentaram resultados semelhantes ao Provaso®. Tais ganhos com uso do lodo de curtume podem estar relacionados ao teor de nitrogênio presente neste resíduo, que promove incrementos no desenvolvimento do caule (REBOUÇAS et al., 2010). 
Tabela 5: Médias dos valores de percentagem de emergência (EMER); altura da plântula (AP); diâmetro do caule (DC); diâmetro da copa (DCOP); comprimento da raiz (CRA) e; número de folhas (NF) de plântulas de pimenta malagueta sob diferentes substratos.

\begin{tabular}{|c|c|c|c|c|c|c|}
\hline Tratamento & EMER & $\mathrm{AP}$ & DC & DCOP & CRAIZ & $\mathrm{NF}$ \\
\hline the & $\begin{array}{c}\% \\
594 *\end{array}$ & $23.99 *$ & $0.23 *$ & $1306 *$ & 2720 & $\overline{-}$ \\
\hline 1D & 39,4 & 25,99 & 0,25 & 15,00 & 37,28 & 2,0 \\
\hline TL10 & $59,9^{*}$ & 29,09 & 0,47 & $17,58^{*}$ & 44,56 & $3,5^{*}$ \\
\hline TL30 & $69,8^{*}$ & 31,50 & 0,57 & 23,00 & 50,20 & 4,2 \\
\hline TL50 & $52,1^{*}$ & 33,33 & 0,65 & 24,90 & 56,03 & 4,6 \\
\hline TL70 & $59,9 *$ & 34,93 & 0,71 & 26,10 & 63,55 & 4,6 \\
\hline TL90 & $62,0^{*}$ & 32,98 & 0,64 & 21,65 & 52,20 & $3,9^{*}$ \\
\hline TP & 28,1 & 34,85 & 0,72 & 28,60 & 53,90 & 5,2 \\
\hline Media & 55,89 & 32,52 & 0,57 & 22,13 & 51,10 & 4,12 \\
\hline $\mathrm{CV}(\%)$ & 18,02 & 12,93 & 21,54 & 18,58 & 18,22 & 12,82 \\
\hline
\end{tabular}

Médias seguidas por * na coluna são estatisticamente diferentes do tratamento com Provaso (TP) ao nível de $5 \%$ de probabilidade pelo teste de Dunnett.

Tabela 6: Médias dos valores de matéria fresca da parte aérea (MFPA); matéria fresca da raiz (MFR); matéria seca da parte aérea (MSPA); matéria seca da raiz (MSR) e; índice de qualidade de Dickso (IQD) de plântulas de pimenta malagueta sob diferentes substratos.

\begin{tabular}{cccccc}
\hline Tratamento & MFPA & MFR & MSPA & MSR & $\begin{array}{c}\text { IQD } \\
\left(* 10^{5}\right)\end{array}$ \\
\hline TB & $9,0289^{*}$ & 4,4875 & $3,4385^{*}$ & 1,5292 & $4,6596^{*}$ \\
TL10 & $19,7525^{*}$ & 5,0900 & $4,8225^{*}$ & 2,6300 & $11,9250^{*}$ \\
TL30 & $37,2750^{*}$ & 27,9725 & $8,0250^{*}$ & 6,5700 & 27,4290 \\
TL50 & $45,6275^{*}$ & 23,7050 & $10,6555^{*}$ & 7,9500 & 36,2535 \\
TL70 & $48,6475^{*}$ & 26,1100 & $11,3675^{*}$ & 8,2975 & 39,4253 \\
TL90 & $36,7375^{*}$ & 14,8150 & $9,1075^{*}$ & 5,4400 & 27,7391 \\
TP & 79,1225 & 18,7850 & 18,8975 & 7,7850 & 56,1708 \\
\hline Média & 39,46 & 17,28 & 9,47 & 5,74 & 29,09 \\
\hline CV $(\%)$ & 25,56 & 45,48 & 17,58 & 45,71 & 39,52
\end{tabular}

Médias seguidas por * na coluna são estatisticamente diferentes do tratamento com Provaso (TP) ao nível de $5 \%$ de probabilidade pelo teste de Dunnett.

É válido destacar que plantas com maior diâmetro de caule possuem maior aptidão à sobrevivência, visto que apresentam maior capacidade de formação e de crescimento de novas raízes (TAIZ e ZEIGER, 2004). Isso permite inferir que a adição do lodo de curtume ao Bioplant ${ }^{\circledR}$ pode aumentar o índice de sobrevivência de mudas de pimenta a campo.

O Bioplant ${ }^{\circledR}$, com ou sem adição de lodo de curtume, não proporcionou um bom acúmulo de matéria fresca e seca da parte aérea em comparação ao Provaso®. O Bioplant ${ }^{\circledR}$ possui teor de nitrogênio inferior ao Provaso ${ }^{\circledR}$ (Tabelas 3 e 4), talvez por isso não proporcionou um acúmulo de massa fresca e seca da parte aérea similar ao outro substrato comercial. O nitrogênio é um dos principais elementos responsáveis pelo ganho de massa foliar (CARNEVALI et al., 2014).

Por outro lado, a adição do lodo de curtume aumenta os níveis de sódio no substrato, o qual pode ter ocasionado distúrbios nutricionais em função da 
competição entre este íon e os nutrientes $\mathrm{N}$, $\mathrm{P}, \mathrm{K}$, e Ca pelo mesmo sítio de absorção, inibindo a absorção destes elementos (COELHO et al., 2017). Esse desbalanceamento nutricional pode ter afetado o desempenho das plântulas em relação aquelas submetidas ao Provaso®.

Para as variáveis de matéria fresca e seca de raiz e comprimento de raiz, a adição de lodo de curtume no Bioplant ${ }^{\circledR}$ reforça a ideia de Almeida et al. (2017), pois parte do substrato comercial que pode ser substituído pelo lodo de curtume, sem comprometer o desenvolvimento do sistema radicular, posto que os resultados para estas dadas características foram similares aos encontrados com substrato Provaso®. Isso colabora com experimento de Berilli et al. (2014) de modo que lodo de curtume pode favorecer o desenvolvimento do sistema radicular de mudas de café conilon devido ao elevado teor de matéria orgânica e nutrientes.

Assim como os estudos de Berilli et al. (2019) que observaram ser o lodo de curtume quando associado ao composto de lixo urbano responsável pela melhora significativa do sistema radicular de plântulas de pimenta doce, mas divergindo do acúmulo de matéria seca da parte aérea.

Demais estudos também identificaram a importância do lodo de curtume em substituição parcial a adubos comerciais e substratos convencionais, como os de Sales et al. (2018b) no desenvolvimento de plântulas de maracujá (Passiflora edulis) e Castilhos et al. (2002) nas culturas de trigo, alface e rabanete.

O diâmetro da copa demonstra que os tratamentos TB e TL10 não apresentaram resultados satisfatórios em relação ao uso do substrato Provaso ${ }^{\circledR}$, assim como expressado no índice de qualidade de Dickson (IQD), indicando que o Bioplant ${ }^{\circledR}$ necessita de suplementação mineral para atender as necessidades iniciais das plântulas, sendo proporcionada basicamente pelo lodo de curtume.
Costa et al. (2015) verificaram diferenças significativas nos valores de IQD, entre os substratos estudados, sugerindo que o tipo e a qualidade do substrato interferem na qualidade das mudas de tomate cereja. Para mudas de hortaliças supõem-se que valores de IQD sejam realmente baixos, pois apresentam caule mais herbáceo (SANTOS et al., 2016).

O IQD indica que, quanto maior seu valor, melhor será o padrão de qualidade da muda, servindo de parâmetro comparativo entre propostas de substrato para produção de mudas (DICKSON et al., 1960). Portanto, os tratamentos TL30, TL50, TL70 e TL90 se mostraram com potencial para qualidade de mudas de pimenta malagueta similar ao Provaso®.

Pelas análises de regressão foram observadas que todas as características avaliadas apresentaram significância, exceto para percentagem de emergência. Os altos valores para o coeficiente de determinação $\left(\mathrm{R}^{2}\right)$ indicam que as curvas de regressão linear de segunda ordem são representativas para os dados deste experimento. Na figura 1 são apresentadas as análises de regressão para as características biométricas das plântulas de pimenta.

Ao observar as curvas de tendência, nota-se um padrão de resposta semelhante entre estes parâmetros, de forma que as menores concentrações de lodo de curtume afetaram positivamente o crescimento das plântulas, ao passo que acima de um nível ótimo, as maiores proporções desse resíduo influenciaram negativamente.

Isso indica que a adição de lodo de curtume em mistura ao Bioplant ${ }^{\circledR}$, para produção de mudas de pimenta malagueta, pode ser benéfico, pois possivelmente fornece maiores quantidades de nutrientes em relação ao uso isolado do Bioplant ${ }^{\circledR}$. $\mathrm{O}$ lodo de curtume é um resíduo rico em nutrientes, como nitrogênio, fósforo, potássio, enxofre e magnésio, que favorecem o desenvolvimento das plantas (BERILLI et al., 2014; 2018b). 
Figura 1: Efeito dos tratamentos sobre as variáveis biométricas das plântulas de pimenta malaqueta. $* 5 \%$ de probabilidade.
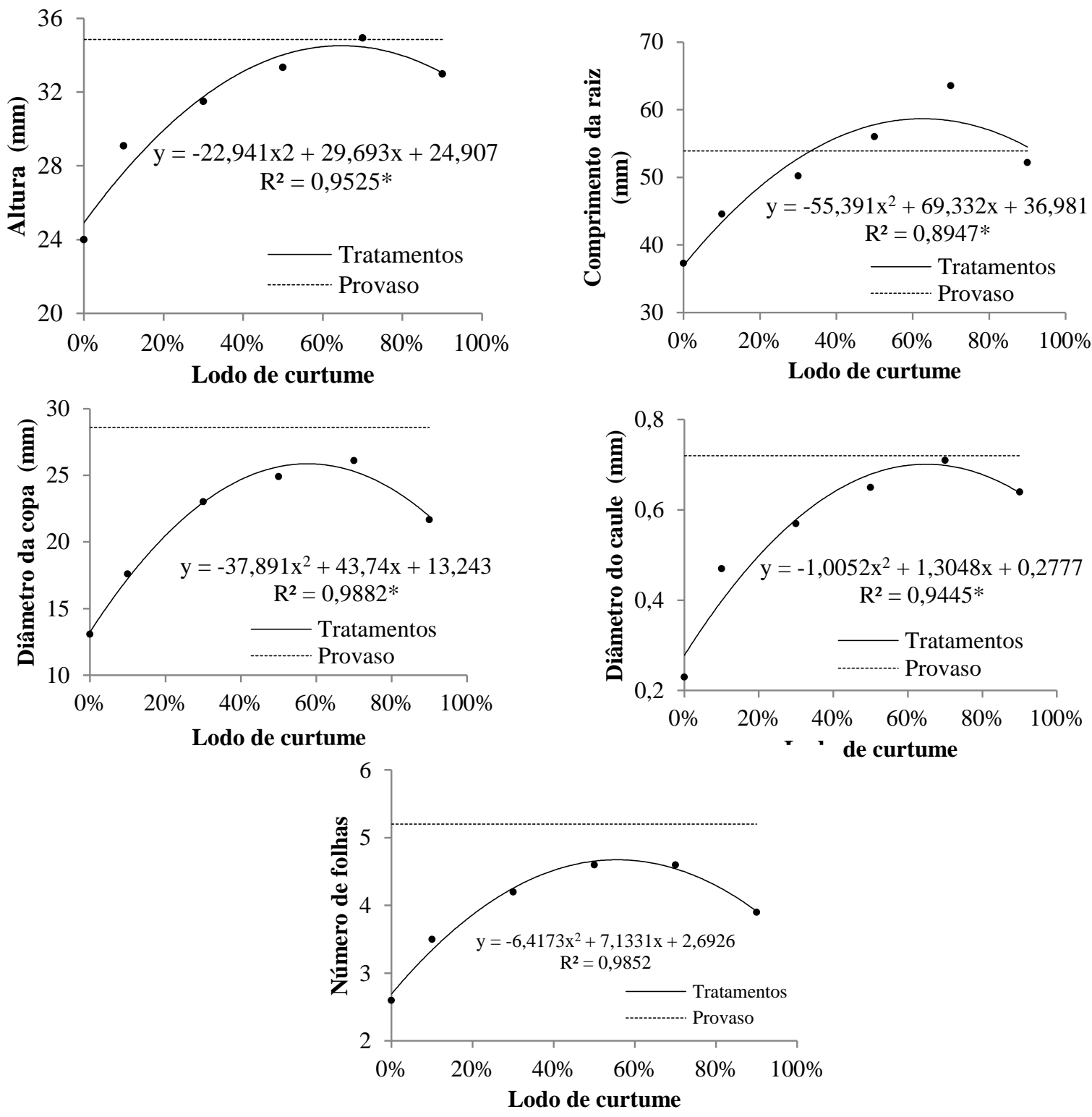

Outros autores também verificaram aumento da fitomassa de mudas ao utilizarem o lodo de curtume nos substratos (BERILLI et al., 2018b; 2019; QUARTEZANI et al., 2018b; SALES et al., 2018a; 2018b). Entretanto tais pesquisadores também notaram que existe um limite para a aplicação de lodo de curtume nos substratos, o qual pode ser visto por meio das análises de regressão da figura 1. Após esse limite, são verificados efeitos deletérios no desenvolvimento das mudas, visualizados a partir da inflexão das curvas de tendência, que podem estar relacionados às atividades do cromo e sódio presentes no resíduo curtumeiro (BERILLI et al., 2014; 2015).

Nota-se um crescimento gradativo para altura de plântula e diâmetro do caule até próximo de $70 \%$ de lodo de curtume no substrato, com posterior decréscimo. Já para o comprimento da raiz, diâmetro da copa e número de folhas, o aumento gradual nestes parâmetros ocorre até entorno de $50 \%$ de lodo de curtume, que após constata-se declínio da curva de tendência (Figura 1). Possivelmente, a adição de lodo em níveis inferiores a 50\% gera insuficiência de nutrientes, enquanto que níveis de lodo de curtume acima de $70 \%$ podem causar 
toxidade às mudas de pimenta. Dessa forma, sugere-se que os níveis ótimos para as características biométricas estejam no intervalo de 50 a $70 \%$ de lodo de curtume adicionado ao Bioplant ${ }^{\circledR}$.

Verifica-se na figura 2 as análises de regressão para as características gravimétricas das plântulas de pimenta. Percebe-se um ganho gradual nos teores de matéria fresca e seca das plântulas de pimenta até a adição de $50 \%$ de lodo nos substratos. Acima de $70 \%$ de lodo percebese um declínio das curvas de tendência, apontando os efeitos negativos do lodo de curtume em alta concentração.

A redução de matéria fresca e seca das plântulas acima do nível ótimo pode ser atribuída à existência de elementos no lodo, atuando negativamente no desenvolvimento das plântulas, pois se espera que maiores quantidades de nutrientes sejam ofertados as plântulas, em maiores quantidades de lodo nos substratos (BERILLI et al., 2015).
Porém, possivelmente destacou-se os efeitos negativos causados pela fitotoxidez do sódio em excesso, promovendo desequilíbrio osmótico nas células dos vegetais (ALMEIDA et al., 2017).

$\mathrm{Na}$ figura 3, semelhantemente ao observado nas figuras anteriores, o índice de qualidade de Dickson (IQD) obteve ganho gradativo até entorno de $50 \%$ de lodo, com queda acentuada a partir dos $70 \%$ desse resíduo no Bioplant®.

Após a inflexão da curva de tendência do IQD, sugere-se a presença de fatores que inibem o desenvolvimento das mudas, como toxidez e desequilíbrios nutricionais ocasionados pelas elevadas concentrações desse resíduo no substrato comercial. A toxidez pode ter sido gerada pelos elementos cromo e sódio presentes nesse resíduo, ao passo que as plântulas de pimenta talvez não suportaram as elevadas cargas de nutrientes dissociados (BERILLI et al., 2018a).

Figura 2: Efeito dos tratamentos sobre as variáveis gravimétricas das plântulas de pimenta malagueta. $* 5 \%$ de probabilidade.
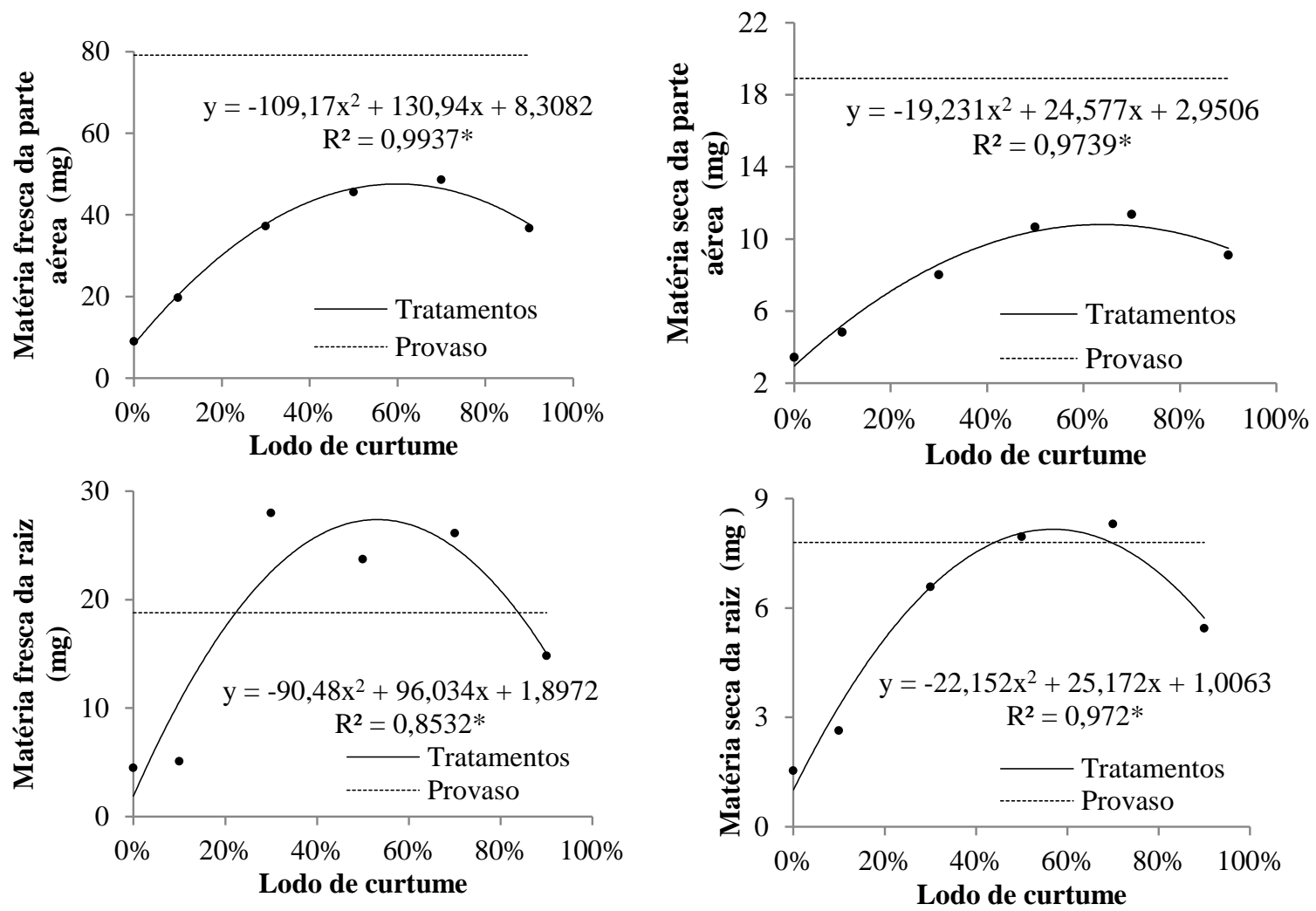
Figura 3: Efeito dos tratamentos sobre o índice de qualidade de Dickson de plântulas de pimenta malagueta. $* 5 \%$ de probabilidade.

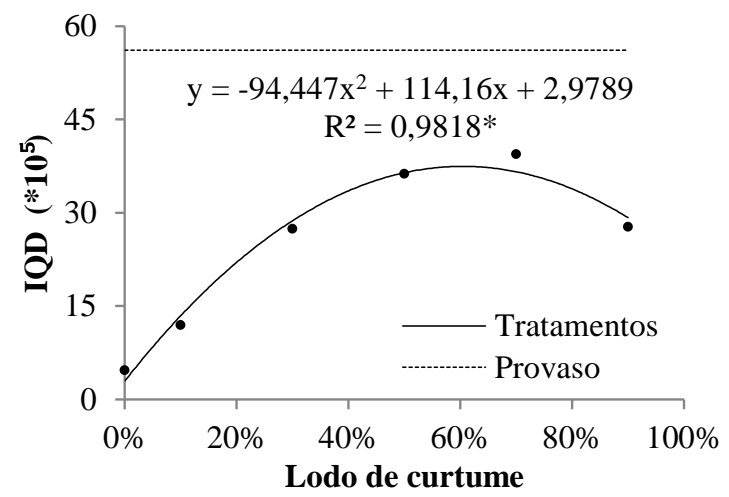

Apesar do potencial do cromo em causar diversos distúrbios morfológicos, fisiológicos e bioquímicos, que limitam os processos metabólicos, vitais às plantas (PLUGARU et al., 2016), possivelmente tais níveis não foram capazes de causar danos às variáveis analisadas. Experimentos realizados por Berilli et al. (2015) demonstraram que teores de cromo entre 0,6 a $46,7 \mathrm{mg} / \mathrm{kg}$ de matéria seca, presentes nas raízes, não interferiram no ganho de matéria de mudas de café conilon. Além de que diversos outros estudos demonstram a baixa translocação do cromo para a parte aérea das plantas (SILVA et al., 2015; SOUZA e SANTOS, 2018).

Isso indica que sódio pode ter promovido os maiores danos às plântulas de pimenta malagueta, acima do nível ótimo. Cabe mencionar que um dos fatores limitantes para produção das olerícolas é a redução do potencial osmótico da solução, ocasionados pelos sais em geral (SECCO et al., 2010). Gupta e Huang (2014) ressaltam que as alterações no potencial hídrico refletem em danos oxidativos em diversos componentes celulares, tais como DNA, proteínas e lipídios, obstruindo as funções celulares vitais.

É valido destacar que as hortaliças são o grupo de plantas mais sensíveis à salinidade, pequenos aumentos nas doses de sais afetam a qualidade e a quantidade da produção dessas culturas (SECCO et al., 2010).

Portanto, isso reforça a ideia dos efeitos negativos do sódio no desenvolvimento e na qualidade das plântulas de pimenta malagueta, ainda corroborando com Martineli et al. (2019), pois em mudas de café conilon, verificaramse que o sódio causou danos significativos às mudas, enquanto que o cromo pode até auxiliar no desenvolvimento dessas plantas.

$\mathrm{Na}$ tabela 7 são apresentadas as concentrações ótimas estimadas de lodo de curtume adicionado ao substrato Bioplant ${ }^{\circledR}$, para as características estudadas, em função de suas equações de estimativas.

Tabela 7: Concentrações ótimas estimadas para lodo de curtume \%(Xv) e valores máximos de (Yv) para altura de plântulas (AP); comprimento de raiz (CRA); diâmetro do caule (DC); diâmetro da copa (DCOP); matéria fresca da parte aérea (MFPA); matéria seca da parte aérea (MSPA); matéria fresca da raiz (MFR); matéria seca das raízes (MSR) e; índice de qualidade de Dickson (IQD) de plântulas de pimenta malagueta estimados de acordo com a análise de regressão lineares de segunda ordem.

\begin{tabular}{ccc}
\hline Parâmetro & Xv (\%) & Yv \\
AP $(\mathrm{mm})$ & 65 & 34,51 \\
CRA $(\mathrm{mm})$ & 63 & 58,68 \\
DC $(\mathrm{mm})$ & 65 & 0,70 \\
DCOP $(\mathrm{mm})$ & 58 & 25,87 \\
MFPA $(\mathrm{mg})$ & 60 & 47,5710 \\
MSPA $(\mathrm{mg})$ & 64 & 10,8029 \\
MFR $(\mathrm{mg})$ & 53 & 27,3794 \\
MSR $(\mathrm{mg})$ & 57 & 8,1572 \\
IQD $\left(* 10^{5}\right)$ & 60 & 37,47 \\
\hline
\end{tabular}

Nota-se que uma proporção de 53 a $65 \%$ de lodo de curtume adicionado ao Bioplant® contemplam as maiores médias das características avaliadas, incluindo a melhor proporção de qualidade de mudas, 
sendo essa de $60 \%$ de lodo de curtume. Além disso, os melhores ajustes são observados para diâmetro da copa e massa fresca da parte aérea, com valores de coeficiente de determinação de 0,9881 e 0,9937 , respectivamente.

A melhor proporção que obteve o maior ganho de massa fresca da parte aérea, em função de sua equação de estimativa, foi de $60 \%$ de lodo de curtume e $40 \%$ de Bioplant ${ }^{\circledR}$, resultando em 47,57 mg.

Em função dos resultados obtidos, é possível afirmar que o substrato comercial Bioplant ${ }^{\circledR}$ necessita de suplementação mineral para atender as necessidades iniciais das plântulas, ficando aquém dos substratos com Bioplant ${ }^{\circledR}$ adicionados de lodo de curtume. Silva Neto et al. (2013), em estudo sobre a influência dos substratos alternativos para produção de pimenteira ornamental (Capsicum annuum L.), concluíram que a combinação de substratos comerciais com substratos alternativos pode colaborar com a diminuição de despesas, assim como aumento da produção, enquanto o uso apenas de areia lavada ou terra vegetal não favorecem o desenvolvimento de mudas de pimenteira ornamental.

\section{CONCLUSÃO}

O aproveitamento do lodo de curtume como complemento ao substrato comercial Bioplant®, para produção de mudas de pimenta malagueta, mostrou-se viável do ponto de vista agrícola, nas proporções de 53 a $65 \%$ desse resíduo no substrato, pois promoveram uma boa qualidade e satisfatório desenvolvimento das mudas em relação ao uso do Provaso®.

\section{REFERÊNCIAS}

ALMEIDA, R. N.; FERRAZ, D. R.; SILVA, A. S.; CUNHA, E. G.; VIEIRA, J. C.; SOUZA, T. S.; BERILLI, S. S. Utilização de Lodo de Curtume em Complementação ao Substrato Comercial na
Produção de Mudas de Pimenta Biquinho. Revista Scientia Agraria, v. 18, n.1, p. 2033, 2017.

ARAÚJO, E. F.; AGUIAR, A. S.; ARAUCO, A. M. S.; GONÇALVES, E. O.; ALMEIDA, K. N. S. Crescimento e qualidade de mudas de paricá produzidas em substratos à base de resíduos orgânicos. Nativa, v. 5, n. 1, p. 16-23, 2017.

BERILLI, S. S.; QUIUQUI, J. P. C.; REMBINSKI, J.; SALLA, P. H. H.; BERILLI, A. P. C. G.; LOUZADA, J. M. Utilização de lodo de curtume como substrato alternativo para produção de mudas de café conilon. Coffee Science, v. 9, n. 4, p. 472-479, 2014.

BERILLI, S. S.; BERILLI, A. P. C. G.; CARVALHO, A. J. C.; FREITAS, S. J.; CUNHA, M.; FONTES; P. S. F. Níveis de cromo em mudas de café conilon desenvolvidas em substrato com lodo de curtume como adubação alternativa. Coffee Science, v. 10, n. 3, p. 320 - 328, 2015.

BERILLI, S. S.; MARTINELI, L.; FERRAZ, T. M.; FIGUEIREDO, F. A. M. M. A.; RODRIGUES, W. P.; BERILLI, A. P. C. G; SALES, R. A.; FREITAS, S. J. Substrate Stabilization Using Humus with Tannery Sludge in Conilon Coffee Seedlings. Journal of Experimental Agriculture International, v. 21, n. 1, p. 110, 2018a.

BERILLI, S. S.; SALES, R. A.; PINHEIRO, A. P. B.; PEREIRA, L. C.; GOTTARDO, L. E.; BERILLI, A. P. C. G. Componentes fisiológicos e crescimento inicial de mudas de palmeira-garrafa em resposta a substratos com lodo de curtume. Scientia Agraria, Curitiba, v. 19, n. 1, p. 94-101, 2018b.

BERILLI, S. S.; VALADARES, F, V.; SALES, R. A.; ULISSES, A. F.; PEREIRA, R. M.; DUTRA, G. J. A.; SILVA, M. W.; BERILLI, A. P. C. G.; SALLES, R. A.; ALMEIDA, R. N. Use of tannery sludge 
and urban compost as a substrate for sweet pepper seedlings. Journal of Experimental Agriculture International, v. 34, n. 4, p. 19, 2019.

CARNEVALI, T. O.; VIEIRA, M. C. V.; CARNEVALI, H. H. S.; GONÇALVES, W. V.; ARAN, H. D. V. R.; ZARATE, N. A. H. Adubos orgânicos na produção de biomassa de Schinus terebinthifolius Raddi (pimenta rosa). Cadernos de Agroecologia, v. 9, n. 4, p. 1-10, 2014.

CASTILHOS, D. D.; TEDESCO, M. J.; VIDOR, C. Rendimentos de Culturas e Alterações Químicas do Solo Tratado com Resíduos de Curtume e Crômio Hexavalente. Revista Brasileira de Ciência do Solo, v. 26, p. 1083-1092, 2002.

COELHO, D. S.; SIMÕES W. L.; SALVIANO, A. M.; SOUZA, M. A.; SANTOS, J. E. Acúmulo e distribuição de nutrientes em genótipos de sorgo forrageiro sob salinidade. Revista Brasileira de Milho e Sorgo, v. 16, p. 178-192, 2017.

COMÉRIO, M.; BERILLI, S. S.; LIMA, C. F.; PINHO, L. G. R.; PEREIRA, L. C.; PINHEIRO, A. P. B.; BERILLI, A. P. C. G.; OLIVEIRA, E. C.; ARAUJO, F. O. Efeito da adubação foliar com lodo de curtume na brotação de secções de caule de abacaxizeiro para produção de mudas.

Revista Ifes Ciência, v. 5, n. 1, p. 170-179, 2019.

COSTA E; SANTO TLE; SILVA AP; SILVA LE; OLIVEIRA LC; BENETT CGS; BENETT KSS. Ambientes e substratos na formação de mudas e produção de frutos de cultivares de tomate cereja. Horticultura Brasileira, v. 33, p. 110-118, 2015.

DASSIE, L. A.; ALEMAN, C. C.; MOREIRA, A. C. M.; MIGNACCA, F. A.; ZANFOLIN, P. R. L.; CARVALHO, P. R. Produção irrigada de mudas de pimenta dedo de moça (capsicum baccatum).
Colloquium Agrariae, v. 13, n. 3, p.128$131,2017$.

DIAS, M. A.; LOPES, J. C.; CORRÊA, N. B.; CUNHA, D.; DIAS, D. C. F. S.

Germinação de sementes e desenvolvimento de plantas de pimenta malagueta em função do substrato e da lâmina de água. Revista Brasileira de Sementes, v. 30, n. 3, p. 115121, 2008.

DICKSON, A.; LEAF, A. L.; HOSNER, J. F. Quality appraisal of white spruce and white pine seedling stock in nurseries.

Forestry Chronicle, v. 36, n. 1, p. 10-13, 1960.

GUPTA, B.; HUANG, B. Mechanism of salinity tolerance in plants: physiological, biochemical, and molecular characterization. International Journal of Genomics, v. 1, p. 1-18, 2014.

LABOURIAU, L. G. A germinação das sementes. Lima: Secretaria Geral da OEA, 1983. (OEA Serie de Biologia. Monografia, 24).

MARTINELI, L.; BERILLI, S. S.; TERCEIRO, L. G. F. S.; FELBERG, N. P.; SALES, R. A.; FERNANDES, S. P.; OLIVEIRA, D. S. Influência do cromo e sódio presentes no lodo de curtume desidratado, no ganho de matérias em mudas de café conilon. In: SIMPÓSIO DE PESQUISA DOS CAFÉS DO BRASIL, 10., 2019, Vitória. Anais... Brasília, DF: Embrapa Café, 2019, 6 p.

NEITZKE, R. S.; FISCHER, S. Z.; VASCONCELOS, C. S.; BARBIERI, R. L.; TREPTOW, R. O. Pimentas ornamentais: aceitação e preferências do público consumidor. Horticultura Brasileira, v. 34, p. 102-109, 2016.

OLIVEIRA, D. L. S; LO MONACO, P. A. V.; KRAUSE, M. R; MENEGHELLI, L. A. M.; GARCIA, W. A.; CALMON, J. M. I. Resíduos agrícolas como substratos alternativos na produção de mudas de 
beterraba. Revista Cadernos de Agroecologia, v. 13, n. 1, 2018.

OZA, E. F.; LO MONACO, P. A. V.; SANTOS, M. M.; ROSADO, T. L.; KRAUSE, M. R.; GARCIA, W. A. Aproveitamento de escória de siderurgia em substratos alternativos para produção de mudas de pimenteira Dedo-de-moça. Rev. Ceres, v. 65, n. 1, p. 104-109, 2018.

PLUGARU, S.; ORBAN, M.; SARB, A.; RUSU, T. Chromium: toxicity and tolerance in plants. A review. Journal of

Environmental Research and Protection, v. 13, n. 4, p. 13-18, 2016.

QUADRO, M. S.; ANDREAZZA, R.; TEDESCO, M. J.; GIANELO, C.;

BARCELOS, A. A.; BORTOLON, L.

Teores de cromo ligados aos óxidos de ferro em áreas de descarte de lodo de curtume.

Eng. Sanitária Ambiental, v. 23, n. 1, p. 63-67, 2018.

QUARTEZANI, W. Z.; SALES, R. A.; BERILLI, S. S.; PLETSCH, T. A.; RODRIGUES, W. P.; CAMPOSTRINI, E.; BERNADO, W. P.; OLIVEIRA, E. C.; HELL, L. R.; MANTOANELLI, E. Effect of different sources of organic matter added to the substrate on physiological parameters of clonal plants of conilon coffee.

Australian Journal of Crop Science, v. 12, n. 8, p. 1328-1334, 2018.

R Core Team. R: A language and environment for statistical computing. $R$ Foundation for Statistical Computing, Vienna, Austria, 2016. Disponível em http://www.R-project.org/. Acesso 14 mar. 2020.

REBOUÇAS, J. R. L., DIAS, N. S., GONZAGA, M. I. S., GHEYI, H. R. e SOUSA NETO, O. N. Crescimento do feijão-caupi irrigado com água residuária de esgoto doméstico tratado. Revista

Caatinga, v. 23, n. 1, p. 97-102, 2010.
ROCHA NETO, O. G.; FIGUEIRÊDO, F. J. C.; VIÉGAS, I. J. M.; BRASIL, E. C.; POLTRONIERI, L. S.; CARVALHO, J. E. U. de. Recomendações para o cultivo da pimenta longa (Piper hispidinervium C.DC.) no Estado do Pará. Belém, PA: Embrapa Amazônia Oriental, 2005. 11 p. (Embrapa Amazônia Oriental. Circular técnica, 39).

ROCHA, S. M. B.; ANTUNES, J. E. L.; SILVA, A. V. C. R.; OLIVEIRA, L. M. S.; AQUINO, J. P. A.; MELO, W. J.; FIGUEIREDO, M. V. B.; ARAUJO, A. S. F. Nodulation, nitrogen uptake and growth of lima bean in a composted tannery sludgetreated soil. Ciência Rural, v. 49, n. 11, p. 1-7, 2019.

SALES, R. A.; SALES, R. A.; NASCIMENTO, T. A.; SILVA, T. A.; BERILLI, S. S.; SANTOS, R. A. Influência de diferentes fontes de matéria orgânica na propagação da Schinus Terebinthifolius Raddi. Scientia Agraria, v. 18, n. 4, p. 99106, 2017.

SALES, R. A.; ROSSINI, F. P.; BERILLI, S. S.; GALVÃO, E. R.; MENDES, T. P.; BERILLI, A. P. C. G.; SALLES, R. A.; SALES, R. A.; QUARTEZANI, W. Z.; FREITAS, S. J. Foliar Fertilization Using Liquid Tannery Sludge in Conilon Coffee Seedlings Production. Journal of Experimental Agriculture International, v. 22, n. 2, p. 1-8, 2018a.

SALES, R. A.; SALES, R. A.; PRANDO, J. F.; BERILLI, S. S.; BERILLI, A. P. C. G.; COELHO, M. B. Lodo de Curtume como Fonte Alternativa na Composição de Substrato de Mudas de Passiflora Edulis. Revista Ifes Ciência, v. 4, n. 8, p. 107-117, 2018b.

SANTOS, S. T.; OLIVEIRA, F. A.; COSTA, J. P. B. M.; SOUZA NETA, M. L.; ALVES, T. R. C.; COSTA, L. P. Qualidade de mudas de cultivares de tomateiro em função de soluções nutritivas de concentrações crescentes. Revista 
Agroambiente On-line, v. 10, n. 4, p. 326333, 2016.

SECCO, L.B.; QUEIROZ, S.O.; DANTAS, B.F.; SOUZA, Y.A.; SILVA, P.P.

Germinação de sementes de melão (Cucumis melo L.) em condições de estresse salino. Revista Verde, v. 4, n. 4, p. 129$135,2010$.

SHARMA, B.; SARKAR, A.; SINGH, P.; SINGH, R. P. Agricultural utilization of Biosolids: A review on potential effects on soil and plant grown. Waste Management, v. 64, p. 117-132, 2017.

SILVA, J. D. C.; LEAL, T. T. B.; ARAUJO, R. M. A.; GOMES, R. L. F.; ARAUJO, A. S. F.; MELO, W. J.

Emergência e crescimento inicial de plântulas de pimenta ornamental e celosia em substrato à base de composto de lodo de curtume. Ciência Rural, v. 41, n. 3, p. 412417, 2011.

SILVA NETO, J. J.; RÊGO, E. R. do; BARROSO, P. A.; NASCIMENTO, N. F. F.; BATISTA, D. S.; SAPUCAY, M. J. L.; RÊGO, M. M. Influência de substratos alternativos para produção de pimenteira ornamental (Capsicum annuum L.). Revista Agropecuária Técnica, v. 34, n. 1, p. 2129, 2013.

SILVA, E.; SANTOS, P. S.; GUILHERME, M. F. S. Chumbo nas plantas: uma breve revisão sobre seus efeitos, mecanismos toxicológicos e remediação. Grarian Academy, v. 2, n. 3, p. 1-21, 2015.

SILVA, L. G. F.; SALES, R. A.; ROSSINI, F. P.; VITÓRIA, Y. T.; BERILLI, S. S. Emergência e desenvolvimento de plântulas de maracujá-amarelo em diferentes substratos. Energia na Agricultura, v. 34, n. 1, p. 18-27, 2019.

SOUSA, V. F. O.; SANTOS, G. L. Elemento Cromo na Nutrição Mineral de Plantas. Revista da Universidade Vale do Rio Verde v. 16, n. 2, p. 1-7, 2018.
TAIZ, L.; ZEIGER, E. Fisiologia vegetal. Porto Alegre: Artmed, 438 p., 2004.

ZANELLO, C. A.; CARDOSO, J. C. Resíduos compostados como substrato para produção de Petunia x Hybrida. Revista Brasileira de Agropecuária Sustentável, v. 6, n. 3, p. 46-53, 2016. 